\title{
Field test and numerical simulation of preconditioning by hydraulic fracturing in hard rock iron mine
}

\author{
W Li China ENFI Engineering Corporation, China \\ YM Liu China ENFI Engineering Corporation, China \\ XW Chen China ENFI Engineering Corporation, China \\ CN Xia China ENFI Engineering Corporation, China \\ $X$ Yao China ENFI Engineering Corporation, China \\ JW Chu China ENFI Engineering Corporation, China
}

\begin{abstract}
Preconditioning by hydraulic fracturing (HF) is a vital technique for assisted caving in block caving mines with poor caveability. Selection of suitable powerful fracturing equipment and the layout of fracturing boreholes need to be fully considered before industry application. For this study, simulation of the HF process was first conducted to determine rock breakdown pressure. The simulation was based on field tests of HF preconditioning in an iron mine, and included: rock breakdown pressure, fracture orientation and extending range. The results show that the data for rock breakdown pressure obtained during this HF simulation could be a guideline for allowable water pressure when selecting water injection pumps for real field applications. Additionally, rock breakdown pressure increased linearly with fracturing depth and had a maximum value of $31.64 \mathrm{Mpa}$ in these tests. Based on microseism positioning analysis of hydraulic fractures, the maximum extending distance was measured at about $34 \mathrm{~m}$ when the pumping flow rate was $150 \mathrm{~L} / \mathrm{min}$. The extension face of the hydraulic fractures was determined to be horizontal, and this was indirectly verified by the increasing water pressure of a nearby monitoring borehole. The results obtained in this study could be a support for the successful application of preconditioning by hydraulic fracturing in hard rock metal mines.
\end{abstract}

\section{Introduction}

Block caving is an underground mining method with low cost, high efficiency and easy to realize automation (Chitombo G P 2010). It has attracted the attention of international mining communities because smart mass mining for block caving mines would increase their maximum potential output. The block caving mining method is a promising, but high-risk technique. Its successful application is mainly based on having high requirements in orebody occurrence and scale, the rock mass structural and geological conditions, and the in-situ stresses. If these conditions were met, the caving initiation and propagation process could be continuous, and acceptable block size would be produced. If the oversize rate is too high, it would not only hinder the mine's caving continuity and affect annual production capacity, but also increase the necessity for secondary crushing operations. This could result in weakened production safety and diminished economic benefits. Preconditioning by hydraulic fracturing is a new technology initially introduced from the oil and gas industry (Liu et al. 2018). Some block caving mines (He et al. 2016) such as the El Teniente mine and Salvador mines in Chile, the Newcrest Cadia East mine (Lowther et al. 2016) and the Northparkes mine in Australia, have carried out relevant studies and have satisfactorily improved rock caveability, controlled oversize, reduced the likelihood of large seismic 
events occurring in the cave crown and sensitive infrastructure areas, and promoted continuous caving propagation (Cao et al. 2016). The combination of block caving mining with preconditioning technology could be a mass mining method for some hard rock metal mines which have been newly transferred from open pit to underground and have a large production capacity requirement. China's block caving mines, such as Tongkuangyu Copper mine (Liu 2012) and Pulang Copper mine (Liu et al. 2016), will face problems such as deterioration of rock caveability and the appearance of geostress damage on bottom structures after making a transition to greater depths. For this reason, it is necessary to carry out further research-on hard rock preconditioning to fully understand the mechanism and operational procedures, and to provide technical support for safe and efficient mine production in the future.

This paper presents a field test of hard rock preconditioning by hydraulic fracturing carried out in an iron mine, and studies the hydraulic fracturing mechanism and fracturing effect.

\section{$2 \quad$ Engineering background}

The field test site for hydraulic fracturing preconditioning was in an opencast to underground iron mine (shown in Figure 1) located in Anshan city, Liaoning province, northeast China. The mine was transferred to underground in 2012, and mined by the pillarless sublevel caving method from then on. The current actual capacity of 3,500,000 t/a is far less than the designed capacity of 8,000,000 t/a. The mine owner was not satisfied with this production level, and a feasibility research project was proposed to investigate exploitation of the mine using a larger capacity method, such as the block caving method. Based on the orebody occurrence (with an average dip angle of $80^{\circ}$ ) and geological and structural conditions (shown in Figure 2), rock mass properties and in-situ stress, an evaluation on rock caveability was performed. The results showed that the orebody to the west of fault F19 would be easy to cave, the orebody east of fault Fm-1 would be difficult to cave, and the orebody between fault F19 and Fm-1 moderately caveable. In order successfully apply the block caving mining method in this mine, the technology of HF preconditioning to improve rock caveability had be first fully understood, and then the selection of pumping equipment and layout of fracturing boreholes could be rationally designed.

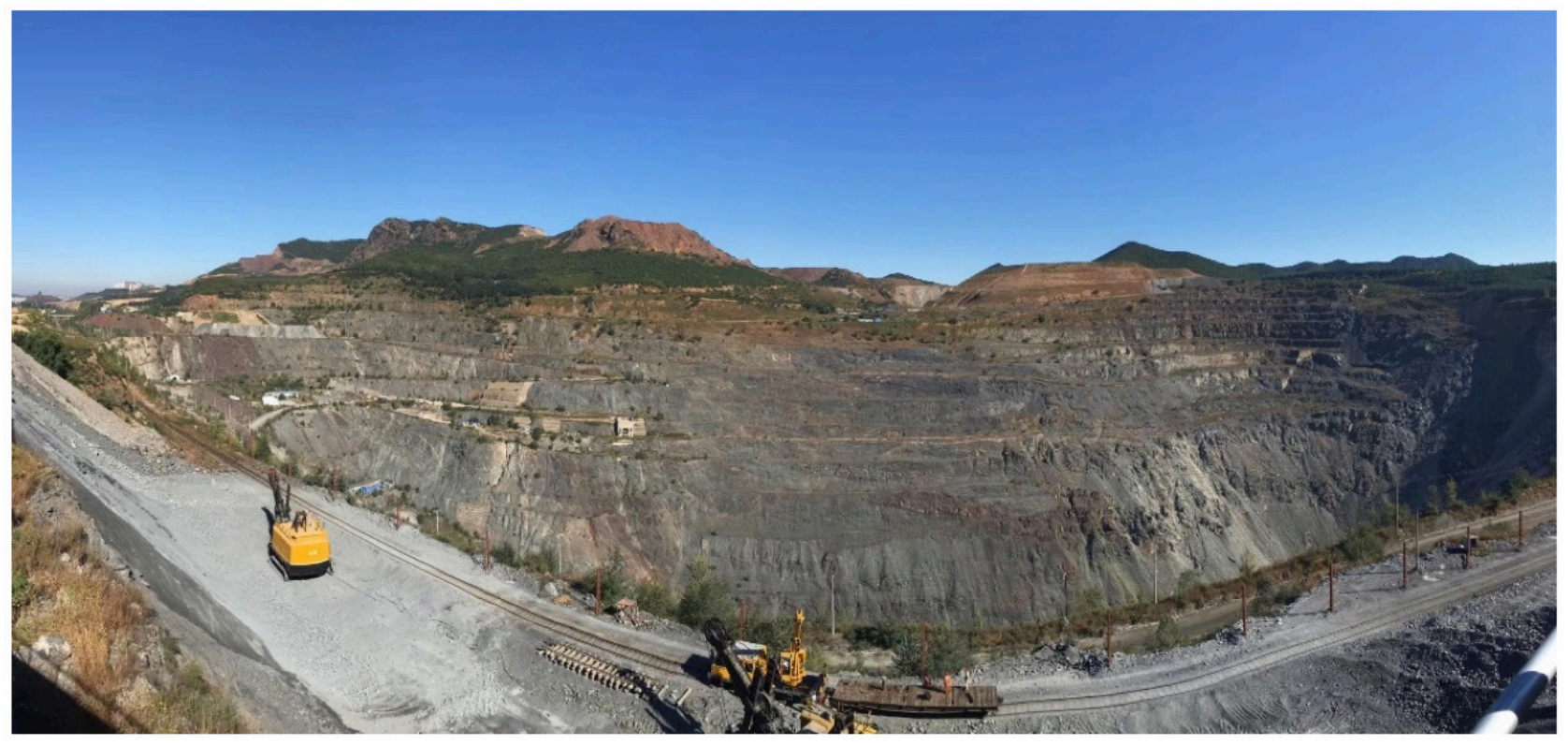

Figure 1 Opencast to underground iron mine 


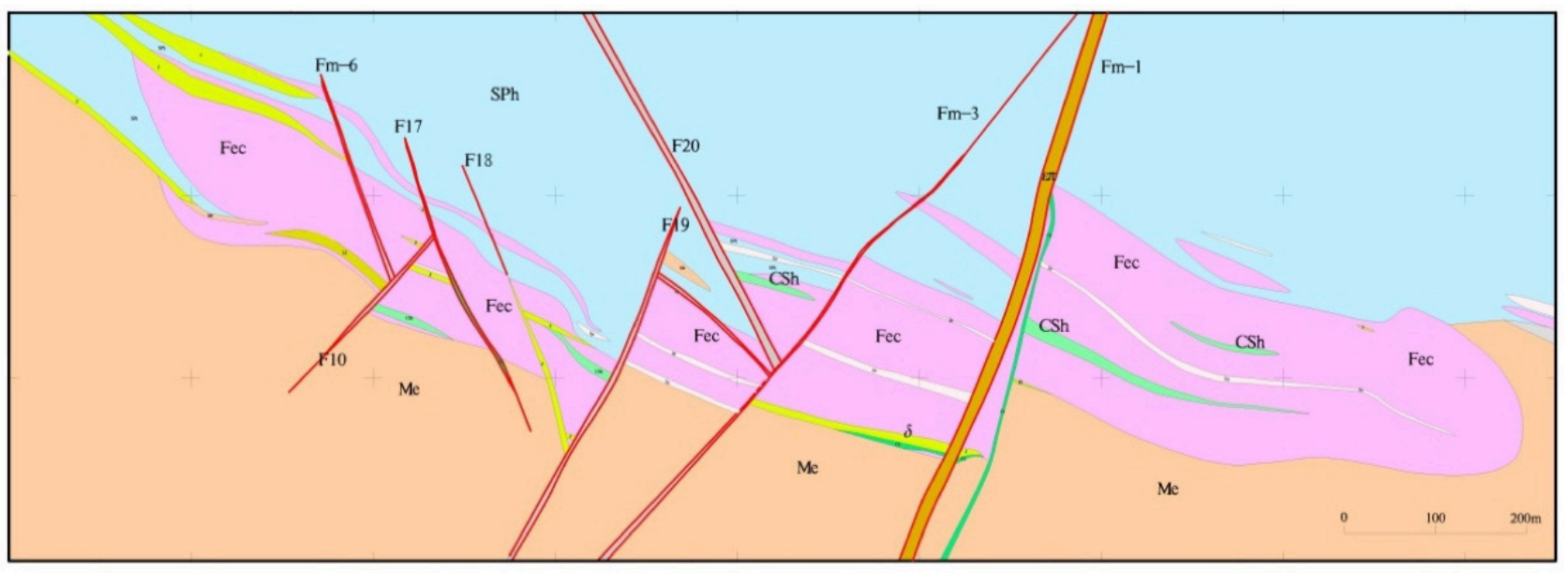

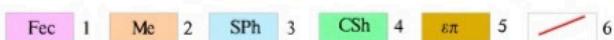

1- Magnetite quartzite ; 2- Mixed rock ; 3- Chlorite phyllite ; 4- Chlorite quartz schist ; 5- Ortho-porphyry ; 6-Fault

\section{Figure 2 Structural and geological map of orebody}

\section{$3 \quad$ Numerical simulation of rock hydraulic fracturing test}

\subsection{Rock model for hydraulic fracturing simulation}

A cubic rock sample containing a prefabricated hole (shown in Figure 3) was created in FLAC ${ }^{3 D}$ numerical simulation software. The fracturing borehole was situated along the central axis of the cubic rock sample. The side-length of the cubic rock sample was $6 \mathrm{~m}$, and the diameter of the fracturing borehole was $91 \mathrm{~mm}$. The Mohr-Coulomb constitutive model for rock was adopted for the simulation. The required rock property input parameters were obtained from physical and mechanical lab tests on borehole core and rock samples collected in the field. The physical and mechanical parameters of the rock are listed in Table 1.

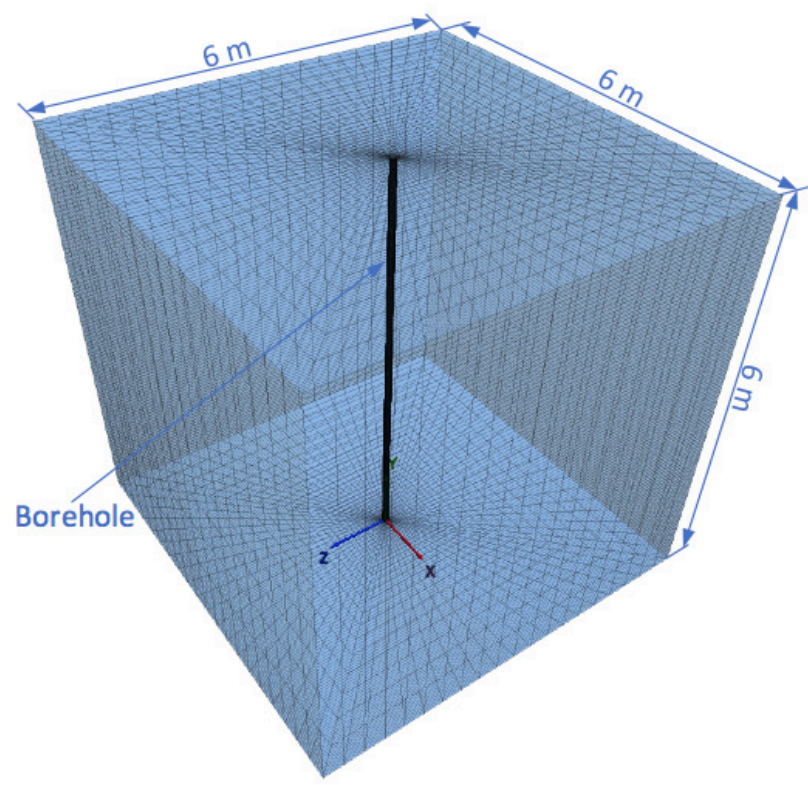

Figure 3 Cubic rock sample for hydraulic fracturing test 
Table 1 Rock physical and mechanical parameters

\begin{tabular}{|c|c|c|c|c|c|c|c|}
\hline Rock type & $\begin{array}{c}\text { Density } \\
\text { /kg/m }\end{array}$ & $\begin{array}{c}\text { Elastic } \\
\text { modulus } \\
\text { /GPa }\end{array}$ & $\begin{array}{c}\text { Poisson } \\
\text { ratio }\end{array}$ & $\begin{array}{c}\text { Internal } \\
\text { friction } \\
\text { angle } \\
/^{\circ}\end{array}$ & $\begin{array}{c}\text { Cohesion } \\
\text { /MPa }\end{array}$ & $\begin{array}{c}\text { Tension } \\
\text { strength } \\
/ \mathrm{MPa}\end{array}$ & $\begin{array}{c}\text { Axial } \\
\text { compression } \\
\text { strength } \\
\text { /MPa }\end{array}$ \\
\hline $\begin{array}{c}\text { Magnetite } \\
\text { Ore }\end{array}$ & 3,380 & 97.32 & 0.19 & 50 & 27.42 & 10 & 129.4 \\
\hline
\end{tabular}

\subsection{Simulation process}

Considering that rock is in a natural geo-stress field environment, the rock block model was first stress initialized according to actual in-situ stress conditions. These were measured by the stress relief method of boreholes drilled horizontally in roadways where vertical stress was about $8 \mathrm{MPa}$, and the minimum and maximum principal stress in the horizontal direction was about $10 \mathrm{MPa}$ and $17 \mathrm{MPa}$, respectively. Then, straddle packers were inserted and water was injected into the packers to make the packer sleeves expand. The process of packer sleeve expansion was simulated by applying gradually increasing pressure (the pressure was increased from 0 to $10 \mathrm{MPa}$ with a gradient of $0.1 \mathrm{MPa}$ ) on the surface of the borehole where it had contact with the packers. Figure 4 shows the X-displacement of the borehole after the straddle packers have been wholly expanded; it shows that the displacement is small, with a maximum value about $5.167 \mu \mathrm{m}$. After a sealed borehole section between two packers was formed, high-pressure water was injected into the sealed section to make a borehole rock fracture. Pressure was gradually applied directly on the surface of the sealed borehole section until rock fracture initiation.
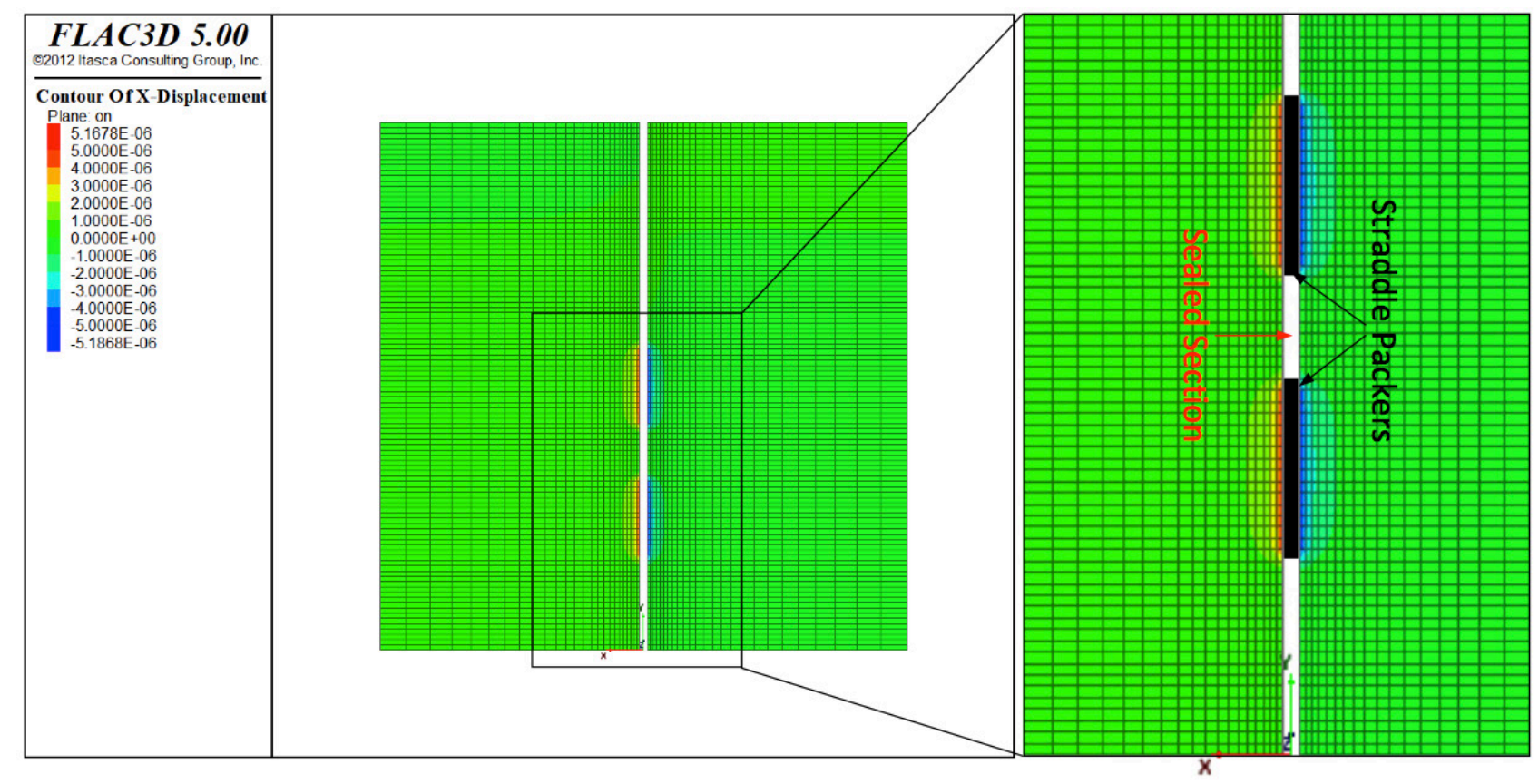

Figure 4 X-displacement of borehole after straddle packers expanded

\subsection{Determination of rock breakdown pressure}

During the HF simulation test, breakdown pressure was fixed as the inner pressure of the borehole when plastic failure zones appeared around the borehole rock. Figure 5 shows the pressure curve of water injection when tension failure zones first appeared. The horizontal axis in Figure 5 indicates the number of loading cycles and the vertical axis indicates the corresponding water injection pressure. It can be seen that when the water injection pressure reached $37.8 \mathrm{MPa}$, tensile failure plastic zones were generated, 
and the borehole water injection pressure was the same as the rock breakdown pressure at this time. This figure is valuable for guiding selection of the allowable water pressure of injection pumps for real field applications.

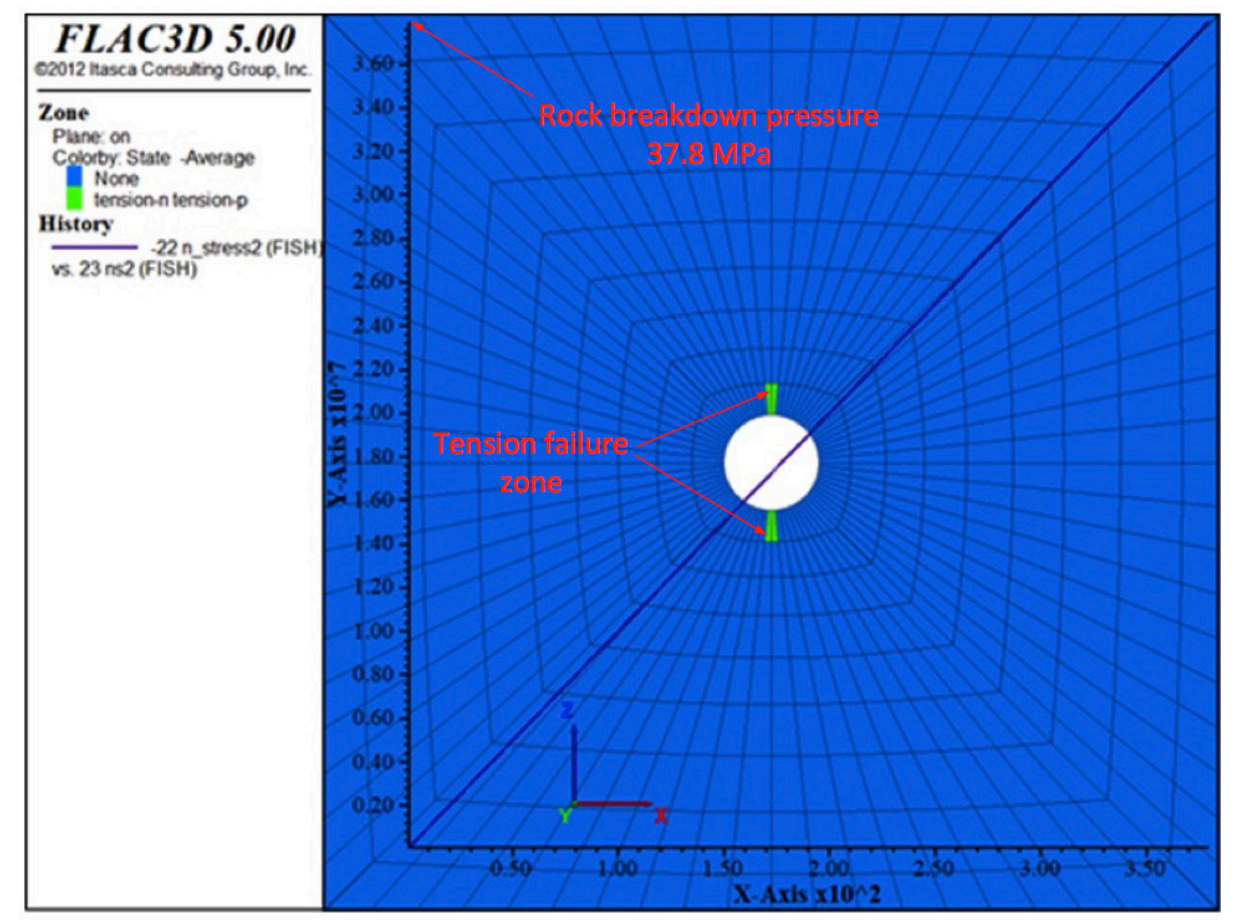

Figure 5 Determination of breakdown pressure during hydraulic fracturing test

\section{$4 \quad$ Field tests of preconditioning by hydraulic fracturing}

\subsection{Site layout for hydraulic fracturing test}

The preconditioning field test by hydraulic fracturing was carried out at a vertical borehole with a diameter of $91 \mathrm{~mm}$ and depth of $306 \mathrm{~m}$, and was located at the intersection of lane A4 and $2^{\#}$ at -195 $\mathrm{m}$ in elevation in an iron mine in Anshan. Eight monitoring boreholes with a diameter of $76 \mathrm{~mm}$ and depth of $126 \mathrm{~m}$ were drilled vertically at the roadways around the fracturing borehole, and they were used for placing downhole sensors to monitor water pressure. The site layout is shown in Figure 6 . The fracturing borehole were placed in the middle, and the distances between the fracturing borehole and the monitoring boreholes are marked in the figure. Some equipment such as pumps, a water tank and monitoring station were placed at the adjacent roadways. As diesel-driven pumps were used in this test, some localized venting practices were taken to guarantee the air quality. Roof brushing work was conducted to produce drilling chambers at roadways where boreholes were to be drilled so that the drilling and fracturing engineering could be carried out. 


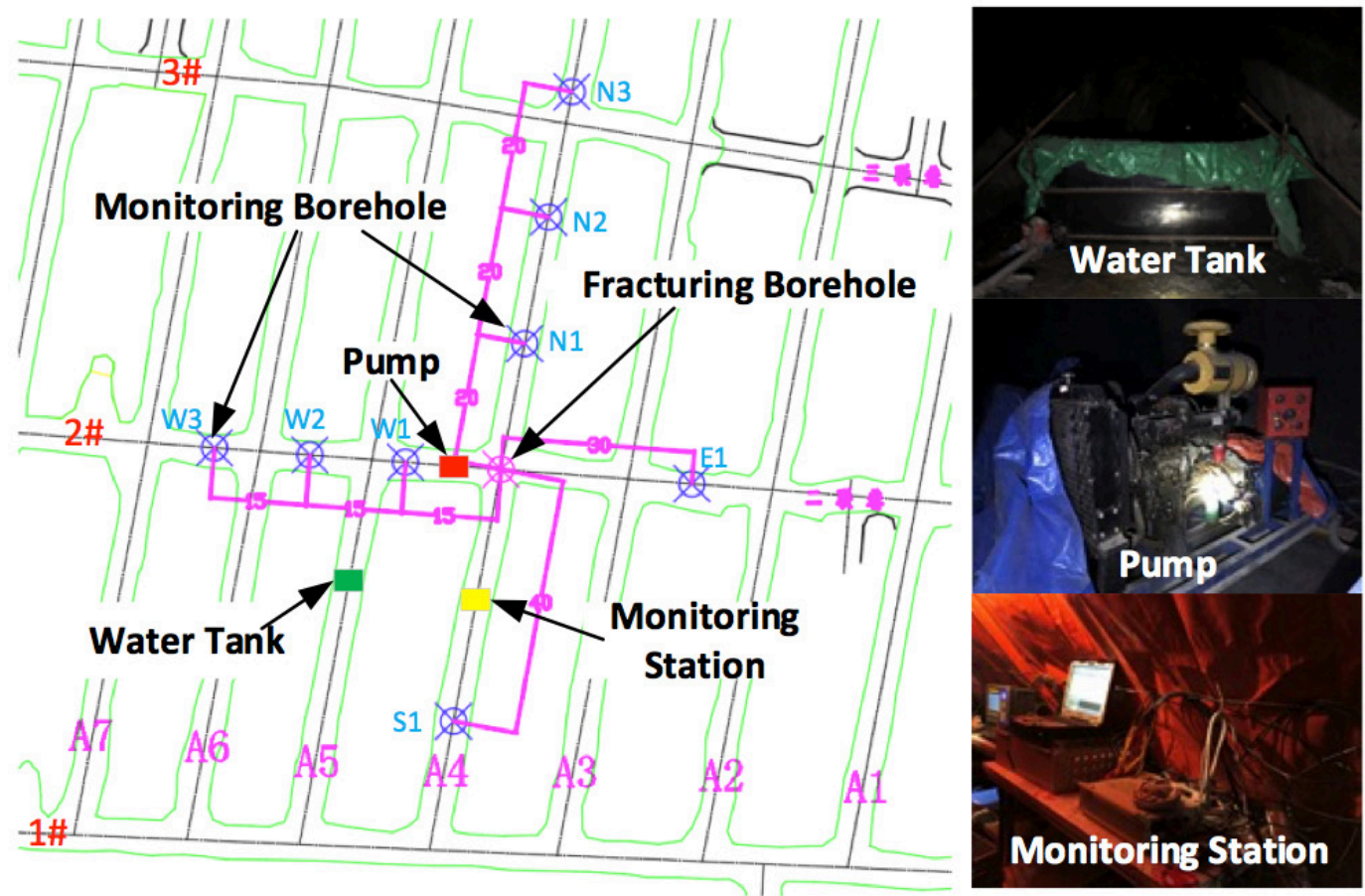

Figure 6 Site layout for hydraulic fracturing test at -195 m level

Figure 7 shows the systematical diagram of the hydraulic fracturing test at the mine site. Four pumps were used during the hydraulic fracturing tests, one for pumping high pressure water to the straddle packers and the other three for isolated boreholes. Considering that the pump's allowable pressure should be higher than the value (37.8 MPa) of rock breakdown pressure obtained from the HF simulation, pumps with a maximum working pressure of $50 \mathrm{MPa}$ and maximum flow rate of $50 \mathrm{~L} / \mathrm{min}$ were chosen for these field tests. Some sensors used to monitor water pressure and flow rate were linked via data transmission cables to an acquisition system placed at the monitoring station. A hoister was used to lift connected hollow drilling rods up and down in the fracturing borehole. A connector was used to link the bottom of drilling rods with the top of the straddle packers, and the channel of hollow drilling rods was used for injecting high pressure water. Figure 8 shows the straddle packers used in this field test, this is a device widely used in deep hole in-situ stress measurement with hydraulic fracturing. The diameter of the straddle packers was $85 \mathrm{~mm}$ and the length of isolated section between two packers was about $50 \mathrm{~cm}$. The material of the packer sleeve was hydrogenated butadiene-acrylonitrile rubber. After the components of the straddle packers were completely assembled, the packers were checked to be sure they were leak proof. 


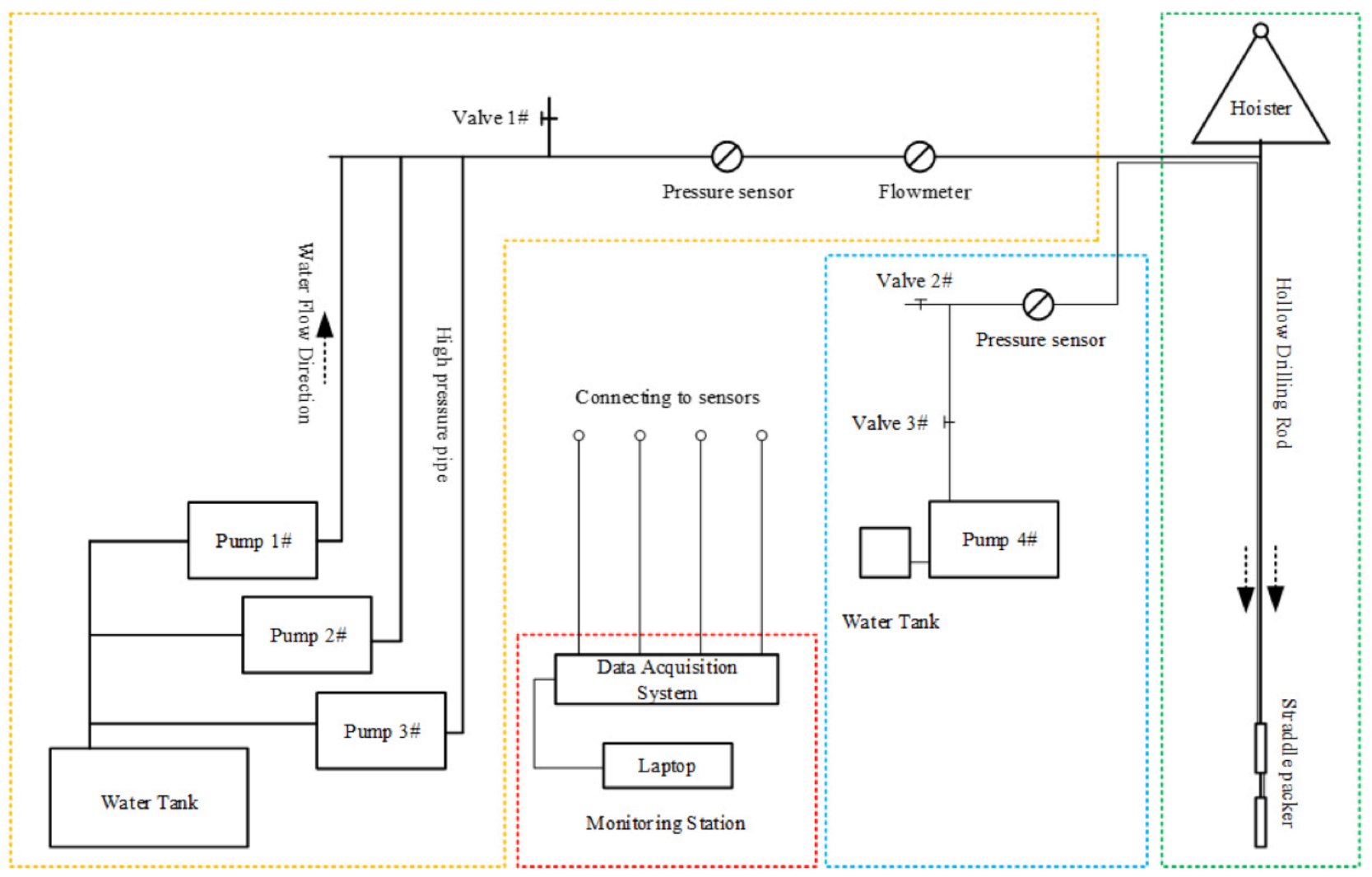

Figure 7 Schematic diagram of hydraulic fracturing test

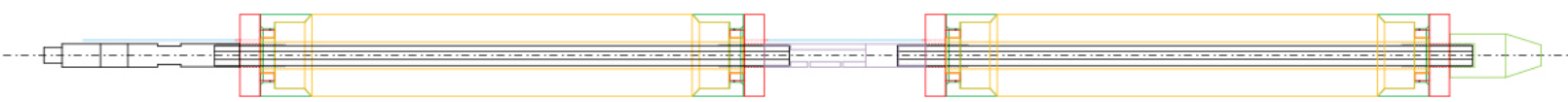

Figure 8 Straddle packers used in the tests

\subsection{Rock breakdown pressure}

Figure 9 shows a typical time-history curve of water pressure monitored in the pipe during a hydraulic fracturing field test. For the first several seconds, the water pressure in the pipe remains stable at a low value as water is continuously pumped into the borehole isolated by the straddle packers. It then increased sharply until the peak value was reached, and finally dropped to a stable value with a small floating band. The water pressure dropped after reaching the peak because a fracture was produced in the borehole rock; the peak value of water pressure is the rock breakdown pressure. Through multiple hydraulic fracturing tests in different sections of the fracturing borehole, rock breakdown pressures at different depths of the borehole were obtained. As shown in Figure 10, general tendency is that rock breakdown pressure increases linearly with fracturing depth. The linear relationship of rock breakdown pressure $(\mathrm{Pb})$ and fracturing depth $(\mathrm{H})$ is: $\mathrm{Pb}=0.0596 \mathrm{H}+13.601$. The maximum rock breakdown pressure obtained at this fracturing borehole was $31.64 \mathrm{MPa}$, which is a little less than the value (37.8 $\mathrm{MPa})$ of rock breakdown pressure obtained from the simulation. This confirms that the rock hydraulic fracturing simulation work could be credible for correct selection of pump working pressure. 


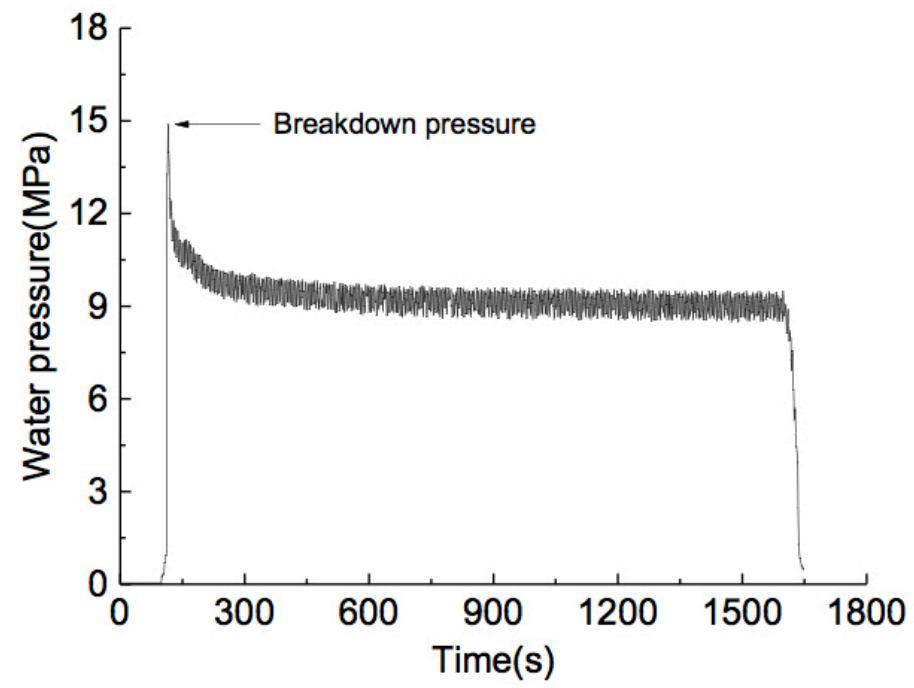

Figure 9 Curve of water injection pressure during a hydraulic fracturing test

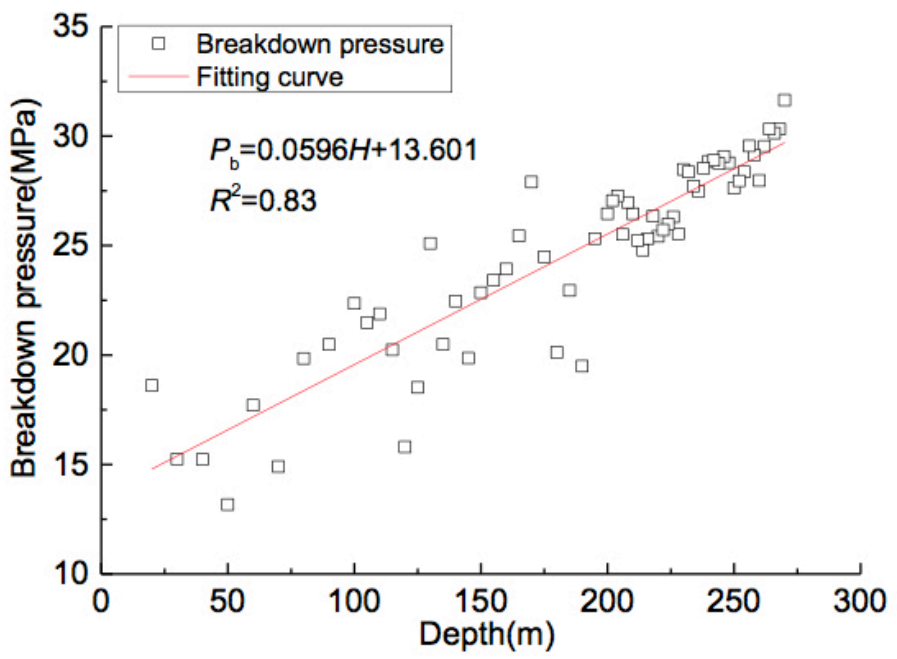

Figure 10 Relationship between rock breakdown pressure and fracturing depth

\subsection{Extending range of hydraulic fractures}

A total of 11 microseism sensors (4 in monitoring boreholes and 7 in roadways at $-195 \mathrm{~m}$ elevation) were arranged around the fracturing borehole to detect seismic events (Joubert 2010). They are denoted with a triangle in Figure 11, which shows a plan graph of microseism signals monitored during hydraulic fracturing field tests. The small dots in the figure represent the microseism signals generated when the rock mass was cracked by high pressure water. The microseism signals were mainly emitted to the northeast and southwest of the fracturing borehole, and an ellipse with a long axis coincided with the direction of the maximum horizontal principal stress $\left(\sigma_{\mathrm{H}}\right)$. Figure 12 shows the microseism-depth distribution maps. For fracturing tests deep in the borehole, the seismic sensors could not effectively capture signals, so there tend to be less positioning points. The microseisms generated by each fracturing test are basically arranged on the same horizontal plane, indicating that the hydraulic fractures are mostly horizontal. Based on the microseism positioning, when the pumping flow rate is $150 \mathrm{~L} / \mathrm{min}$, the maximum fracture propagation distance of hydraulic fractures can reach to $34 \mathrm{~m}$, and the average maximum fracture propagation distance of all 64 fracturing tests is $24.54 \mathrm{~m}$. 


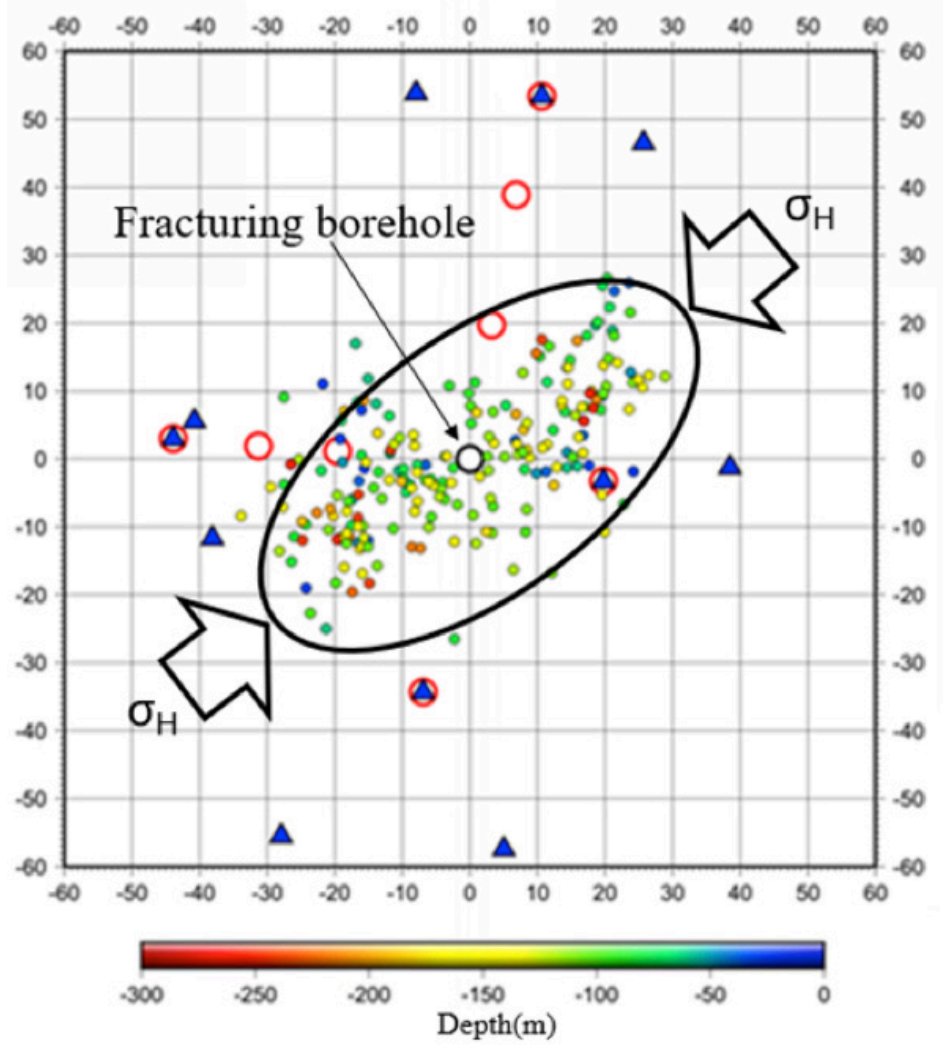

Figure 11 Plane graph of microseismic signals at hydraulic fracturing test site

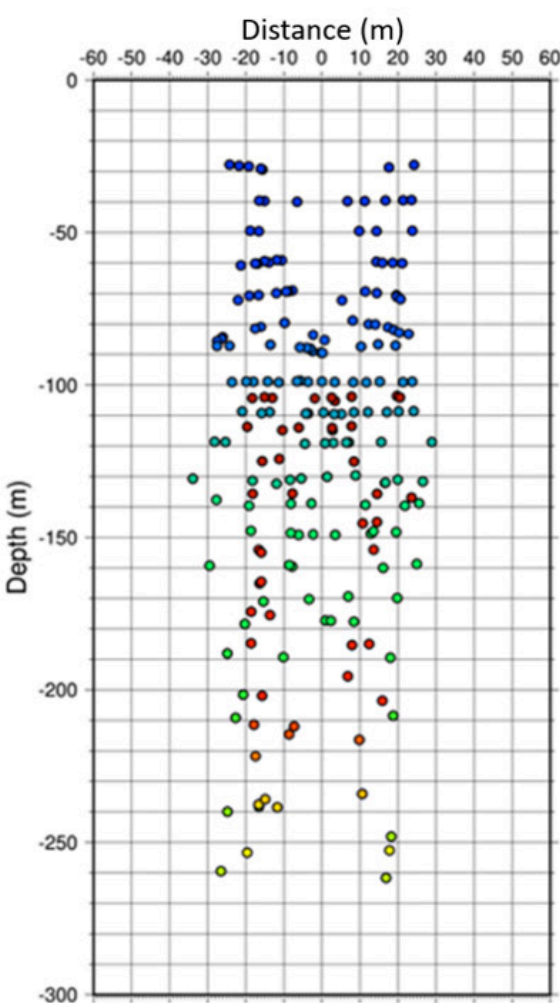

(1) east-west section
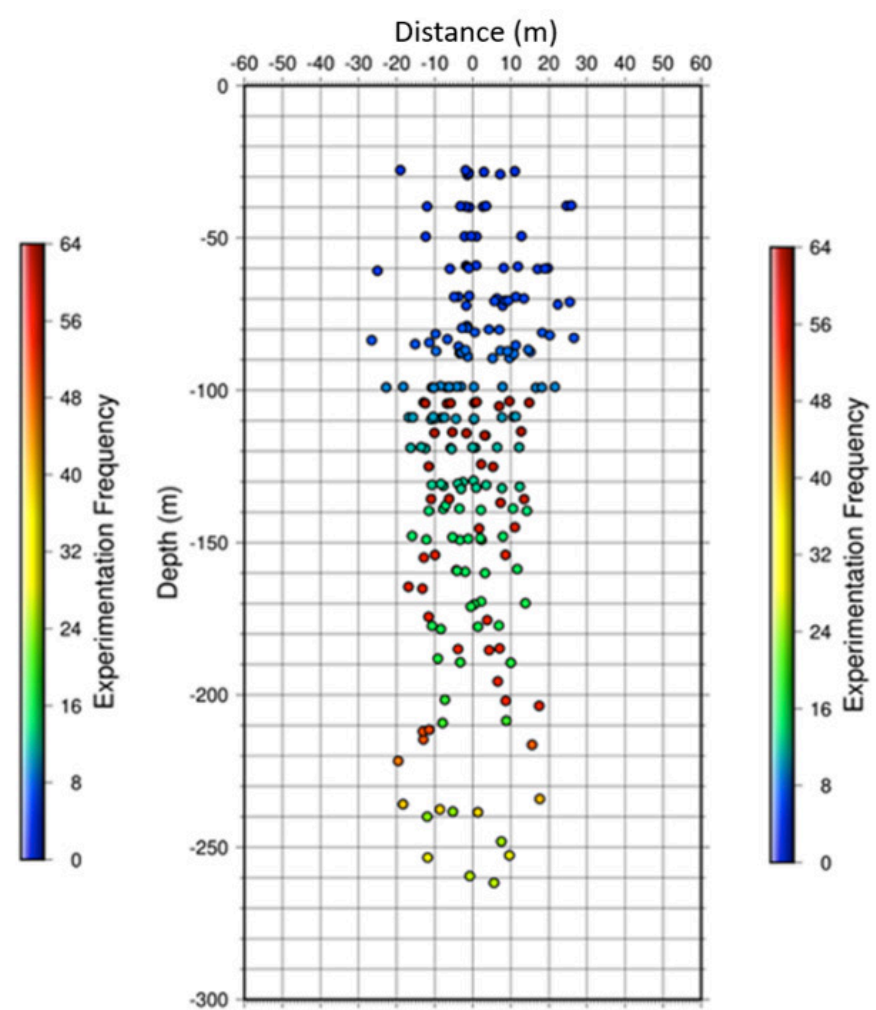

(2) north-south section

Figure 12 Vertical distribution of microseisms

\subsection{Orientation of hydraulic fractures}

The orientation of newly produced hydraulic fractures is a focus of concern because the resulting HF shape and orientation are important for the borehole layout design of preconditioning treatments. In 
this field study, the dominant joint sets found during rock mass structure investigation were vertical. The production of horizontal fractures was more desirable so that they could interact with the vertical joints and the orebody could be cut into small blocks. This would improve the orebody caveability. As no direct method could be used to acquire information about inner fractures, indirect evidence to support horizontal fractures was produced by water level-monitoring in boreholes W1 and E1 (seen in Figure 6). As the water level rose it continuously leaked from these boreholes until it reached $120 \mathrm{~m}$, which was approximately equal to the monitoring depth. When the fracturing depth exceeded $120 \mathrm{~m}$, the water level in all monitoring boreholes did not change. Figure 13 shows the water level condition of monitoring borehole W1 before and after HF tests.

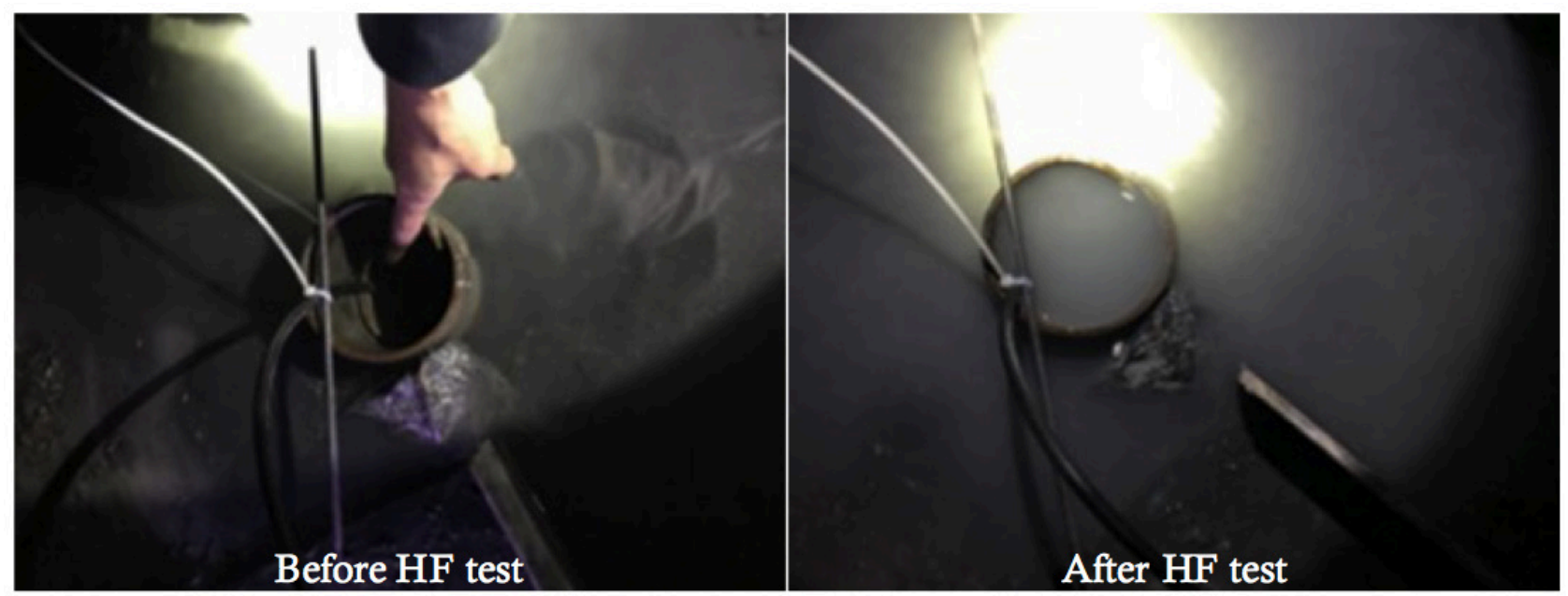

Figure 13 Water condition of the first left monitoring borehole before and after HF tests

\section{Conclusions}

With the aim of analyzing the effects of preconditioning by hydraulic fracturing in hard rock metal mines, a field test in an iron mine was carried out. The breakdown pressure of rock, the extension range and orientation of the hydraulic fractures were analyzed based on field monitoring during the HF tests. The results can be summarized as follows:

- The rock breakdown pressure obtained from the HF simulation is about $37.8 \mathrm{MPa}$, and could be a guideline for allowable water pressure when selecting water injection pumps for real field applications.

- The maximum rock breakdown pressure measured in situ is less than $31.64 \mathrm{MPa}$, which provided a performance basis for the selection of a high-pressure injection pump for the HF preconditioning at this mine. Rock breakdown pressure increased linearly with fracturing depth mainly because of the confining in-situ stress.

- The microseism signals obtained during the HF tests mainly occurred in an ellipse with a long-axis direction of northeast to southwest, which coincided with the direction of the maximum horizontal principal stress.

- At a pumping flow rate of $150 \mathrm{~L} / \mathrm{min}$, the maximum propagation distance of hydraulic fractures can reach $34 \mathrm{~m}$.

- The newly generated fractures in this mine site extended horizontally and the fracture faces were on an approximately horizontal plane.

\section{Acknowledgement}

The authors wish to acknowledge the research sponsor Ansteel Mining Co., Ltd. and Yanqianshan Iron mine for providing financial assistance and the field test site. We also acknowledge the Chinese Academy of Geological Sciences for their help in conducting field tests and analysis. 


\section{References}

Cao H, Yu SB, Wang H, Qin XS \& Yuan Y 2016, 'Research on comprehensive evaluation of caveability of block caving based on MRMR', Chinese Journal of Rock Mechanics and Engineering, vol. 35, no. s2, pp. 4148-4153.

Chitombo GP 2010, 'Cave mining: 16 years after Laubscher's 1994 paper 'Cave mining-state of the art", Mining Technology, vol. 119, no. 3, pp. 132-141.

He Q, Suorineni FT \& Oh J 2016, 'Review of Hydraulic Fracturing for Preconditioning in Cave Mining', Rock Mechanics \& Rock Engineering, vol. 49, no. 12, pp. 4893-4910.

Joubert PJ 2010, 'Microseismic monitoring of hydraulic fractures in block cave mines', Mining Technology, vol. 119, no. 3, pp. 193-197.

Liu HW, Feng XL, Wu M \& Li XH 2016, 'Simulation research on stress change of bottom structure in Pulang copper mine', Ming Research and Development, vol. 36, no. 5, pp. 28-31.

Liu YM, Li W, Chen XW, Xia CN, Fan WL \& Gu XH 2018, 'Research on pre-conditioning technique in hard rock block caving metal mines', China Mine Engineering, vol. 47, no. 3, pp. 59-63.

Liu YM 2012, 'Development trend of block caving method and technical innovation in the second phase of Tongkuangyu copper mine', Mining Technology, vol. 12, no. 3, pp. 1-4.

Lowther RJ, Olivier L, Lett JL \& Brunton I 2016, 'Implementation of a surface-based hydraulic fracturing program to successfully propagate a large cave through hard, competent near-surface rock masses to achieve breakthrough', in C Carr \& G Chitombo (eds), Proceedings of MassMin 2016, Sydney, NSW, pp. 83-95. 